\title{
Comparative Study of Fire Resistance and Char Formation of Intumescent Fire-Retardant Coatings Reinforced with Three Types of Shell Bio-Fillers
}

\author{
Feiyue Wang, Hui Liu and Long Yan *
}

Citation: Wang, F.; Liu, H.; Yan, L. Comparative Study of Fire Resistance and Char Formation of Intumescent Fire-Retardant Coatings Reinforced with Three Types of Shell Bio-Fillers. Polymers 2021, 13, 4333. https:// doi.org/10.3390/polym13244333

Academic Editors: Zhi Li, Jun Sun and Yongqian Shi

Received: 16 October 2021

Accepted: 6 December 2021

Published: 10 December 2021

Publisher's Note: MDPI stays neutra with regard to jurisdictional claims in published maps and institutional affiliations.

Copyright: (C) 2021 by the authors Licensee MDPI, Basel, Switzerland. This article is an open access article distributed under the terms and conditions of the Creative Commons Attribution (CC BY) license (https:/ / creativecommons.org/licenses/by/ $4.0 /)$.
Institute of Disaster Prevention Science and Safety Technology, School of Civil Engineering, Central South University, Changsha 410075, China; wfyhn@163.com (F.W.); lhui0421@163.com (H.L.)

* Correspondence: ylong015@csu.edu.cn; Tel.: +86-181-6365-0767

\begin{abstract}
Three types of shell bio-fillers, including eggshell (CES), conch shell (CHS) and clamshell (CMS), were prepared by cleaning, ultrasonication and pulverizing processes of biowastes, and then applied to intumescent fire-retardant coatings. The effects of shell bio-fillers with different polymorphs on the fire resistance and char-forming of intumescent fire-retardant coatings were investigated by cone calorimeter test, fire protection tests, smoke density test, thermogravimetric analysis (TG), and the fire resistance and char-forming mechanism of bio-fillers in intumescent fireretardant coatings were proposed. The results show that three kinds of bio-fillers exert an excellent synergistic effect on enhancing the fire resistance and char-forming properties of the intumescent fire-retardant coatings, while clamshell has the best synergistic efficiency among the bio-fillers. Especially, IFRC-CMS coating containing $3 \mathrm{wt} \%$ clamshell shows the best fire protection performance and lowest smoke production and heat release, which offers an equilibrium backside temperature of $134.6^{\circ} \mathrm{C}$ at $900 \mathrm{~s}$, a flame-spread rating of 14.4 , and a smoke density rating value of $22.8 \%$. The synergistic efficiency of bio-fillers in the intumescent coatings depends on the polymorphs of $\mathrm{CaCO}_{3}$ in bio-fillers, and aragonite $\mathrm{CaCO}_{3}$ shows a higher synergistic efficiency compared to calcite $\mathrm{CaCO}_{3}$ and the mixture of aragonite and calcite $\mathrm{CaCO}_{3}$. The CMS composed of aragonite shows the best synergistic effect, CHS composed of aragonite and calcite comes second, and CES composed of calcite has the weakest synergistic effect.
\end{abstract}

Keywords: intumescent fire-retardant coatings; shell bio-filler; fire resistance; char formation; synergistic effect

\section{Introduction}

Intumescent fire-retardant coatings are considered one of the most influential and economical materials for reducing fire hazards of buildings owing to their excellent fire resistance and heat-insulation performance, which usually include organic intumescent coatings and inorganic intumescent coatings and are widely used in wood, concrete, steel, etc. [1-3]. Intumescent fire-retardant coatings usually consist of an intumescent fire-retardant system, a binder, a synergist and additives, among which the intumescent fire-retardant system plays a crucial role in the properties of the intumescent fire-retardant coating. The intumescent fire-retardant system is mainly composed of three parts: a gas source, a carbon source, and an acid source, which interact to form an expanding char layer to block the transfer of heat and mass, protecting the substrate from permanent damage during combustion [4,5]. However, the traditional intumescent fire-retardant system composed mainly of APP, PER, and MEL still has the disadvantage of a low flameretardant efficiency, so more efforts have focused on enhancing the fire resistance and char formation of traditional intumescent flame-retardant systems in polymeric materials [1].

Bio-fillers, as an environmentally-friendly material, are widely applied in fire-retardant coatings, plastics, and concrete to enhance the fire resistance, thermal stability, char forma- 
tion, and mechanical performance of the materials owing to their excellent characteristics such as lightweight, high quantity, and affordability [6-8]. Shell bio-wastes including eggshell (CES), conch shell (CHS), and clamshell (CMS) are mainly comprised of calcium carbonate. Generally, calcium carbonate can be classified as amorphous, calcite, aragonite and vaterite, where amorphous is a non-crystalline state and calcite, aragonite, vaterite are crystalline states [9]. Calcite and aragonite are natural calcium carbonates, while vaterite is synthetic calcium carbonate. Numerous studies have reported the application of calcite and aragonite in polymeric materials. Zhou et al. used the $\mathrm{CaCO}_{3}$-containing oil sludge (OS) and carbon black (CB) to prepare EVA/OS/CB composites, and found that the addition of $\mathrm{CaCO}_{3}$-containing OS and $\mathrm{CB}$ could improve the flame retardancy and thermal stability of composites [10]. Zhang et al. studied the adsorption of calcite, aragonite and vaterite for $\mathrm{CH}_{4}$ and $\mathrm{CO}_{2}$ gases and found that aragonite has a stronger catching ability than calcite [11]. Radek et al. synthesized calcium carbonate of calcite, aragonite, and vaterite and investigated the effect of polymorphs calcium carbonate on nano-lime suspensions, and found that the addition of calcium carbonate with aragonite was effective in reducing the propagation of cracks [12]. Liu et al. used argopecten irradians and mactra veneriformis shells to remove phosphate from aqueous solutions and showed that calcium carbonate with calcite has a stronger adsorption for phosphate than calcium carbonate with aragonite [13]. Li et al. used steel fiber-polyvinyl alcohol fiber-calcium carbonate whisker multi scale fiber to reinforce cementitious composites, and the addition of calcium carbonate whisker can effectively enhance the mechanical properties of the composites [14]. In general, $\mathrm{CES}$ is mainly composed of calcite $\mathrm{CaCO}_{3}$, and $\mathrm{CMS}$ primarily consists of aragonite $\mathrm{CaCO}_{3}$, while CHS is composed of a mixture of calcite and aragonite $\mathrm{CaCO}_{3}$. Among them, calcite $\mathrm{CaCO}_{3}$ has strong thermal stability, while aragonite $\mathrm{CaCO}_{3}$ has superior advantages on enhancing the mechanical properties and processing properties of polymeric materials. The enhanced effect of calcium carbonate in polymeric materials varies with the polymorphs of calcium carbonate. However, few studies have reported the effect of polymorphs of calcium carbonate on the fire resistance and char-forming properties of intumescent fire-retardant coatings.

In this study, eggshell, conch shell, and clamshell are used as raw materials to prepare three types of shell bio-fillers through cleaning, ultrasonication, and pulverizing processes. Four kinds of intumescent fire-retardant coatings were prepared with APP-PER-MEL as intumescent flame retardant, shell bio-fillers as synergists, and waterborne epoxy resin as binder, and the effects of bio-filler polymorphs on the combustion properties of intumescent fire-retardant coatings were investigated. Furthermore, thermogravimetric analysis (TG), scanning electron microscopy (SEM), cone calorimeter test, Fourier transform infrared spectroscopy (FTIR), X-ray diffraction analysis (XRD) were used to analyze the synergistic mechanism of different bio-fillers in the intumescent coatings.

\section{Experimental}

2.1. Materials

Eggshell, clamshell, and conch shell were collected from the faculty and staff canteen of Central South University. Waterborne epoxy hardener (Ruicheng Selected New Materials Technology Co., Ltd., Guangzhou, China) used as amine curing agent is combined with waterborne epoxy resin (Ruicheng Selected New Materials Technology Co., Ltd., Guangzhou, China) as a film-forming polymer. The additives including dispersant and defoamer were obtained from Qingdao Xingguo Coatings Co., Ltd., Qingdao, China. The MEL (purity $\geq 99.5 \%$ ), PER (purity: 99.5\%), and APP (water solubility $\leq 0.04 \%$, purity: $99.5 \%$ ) were provided by Hangzhou JLS Flame Retardant Chemical Co., Ltd., Hangzhou, China.

\subsection{Preparation of Materials}

\subsubsection{Preparation of the Shell Bio-Fillers}

Firstly, three kinds of shell biowastes including eggshell, conch shell, and clamshell were washed in deionized water to remove dirt, and then cleaned with $4 \% \mathrm{NaOH}$ to 
remove impurities and organic matter on the surface of bio-fillers. Afterward, the samples were continually washed with deionized water until neutralization, and ultrasonicated for $2 \mathrm{~h}$ in an ultrasonic instrument (Kunshan Ultrasonic Instrument Co., Ltd., Kunshan, China). Thirdly, the samples were dried in $80^{\circ} \mathrm{C}$ oven for $48 \mathrm{~h}$. Lastly, the samples were ground in a planetary ball mill (Nanjing Chishun Science \& Technology Co., Ltd., Nanjing, China), and placed in a shaker (Xinxiang Rucheng Machinery Equipment Co., Ltd., Xinxiang, China) to obtain bio-fillers with a particle size distribution of $50-80 \mu \mathrm{m}$. The resulted samples were named as CES, CHS, CMS, respectively.

\subsubsection{Preparation of Intumescent Fire-Retardant Coatings}

APP, MEL, and PER with a mass ratio of 3:1:1.5 were blended to prepare intumescent fire retardant (IFR), which is mixed with bio-fillers and deionized water to prepare the coating slurry by stirring at $1000 \mathrm{r} / \mathrm{min}$ for $20 \mathrm{~min}$ in a high-speed disperser. Then, waterborne epoxy resin, dispersant, and defoamer were incorporated into the slurry and stirred for $20 \mathrm{~min}$ at $500 \mathrm{r} / \mathrm{min}$. Finally, intumescent fire-retardant coatings were prepared by combining waterborne epoxy hardener and slurry at $500 \mathrm{r} / \mathrm{min}$ for $20 \mathrm{~min}$. The prepared coatings were applied to several plywood boards of different sizes $(150 \mathrm{~mm} \times 150 \mathrm{~mm} \times 4 \mathrm{~mm}$, $75 \mathrm{~mm} \times 75 \mathrm{~mm} \times 4 \mathrm{~mm}, 600 \mathrm{~mm} \times 90 \mathrm{~mm} \times 4 \mathrm{~mm}$ ) at a wet density of $500 \mathrm{~g} / \mathrm{m}^{2}$ and several plywood boards of $300 \mathrm{~mm} \times 150 \mathrm{~mm} \times 4 \mathrm{~mm}$ at a wet density of $250 \mathrm{~g} / \mathrm{m}^{2}$. The intumescent fire-retardant coatings were prepared without bio-filler and with $3 \mathrm{wt} \%$ bio-filler, and the specific formulation is shown in Table 1.

Table 1. Compositions of the intumescent fire-retardant coatings (mass fraction) $\%$.

\begin{tabular}{ccccccc}
\hline Samples & IFR & Bio-Filler & $\begin{array}{c}\text { Waterborne } \\
\text { Epoxy Resin }\end{array}$ & Defoamer & Dispersant & $\begin{array}{c}\text { Waterborne Epoxy } \\
\text { Hardener }\end{array}$ \\
\hline IFRC-0 & 55 & 0 & 40 & 0.5 & 0.5 & 4 \\
IFRC-CES & 52 & 3 & 40 & 0.5 & 0.5 & 4 \\
IFRC-CHS & 52 & 3 & 40 & 0.5 & 0.5 & 4 \\
IFRC-CMS & 52 & 3 & 40 & 0.5 & 0.5 & 4 \\
\hline
\end{tabular}

\subsection{Characterization}

2.3.1. Fourier Transform Infrared Spectroscopy

FTIR tests used KBr pellets in an iCAN9 FTIR spectrometer (Tianjin Nengpu Technology Co., Ltd., Tianjin, China) to characterize char residues and bio-fillers.

\subsubsection{Scanning Electron Microscopy}

SEM was applied to study the micro-morphology of the bio-fillers and char residues in the MIRA 3 LMU scanning electron microscopy (Tescan, Brno, Czech Republic) at a voltage of $20.0 \mathrm{kV}$.

\subsubsection{X-ray Diffraction}

$\mathrm{XRD}$ was tested with conditions of $\mathrm{Cu}-\mathrm{Ka}$ radiation, a rate of $5^{\circ} / \mathrm{min}$, and a range of 5 to $70^{\circ}$ in an Advance D8 XRD diffractometer (Bruker, Fällanden, Switzerland).

\subsubsection{Smoke Density Test}

Smoke density test was used to test maximum light absorption rates and smoke density rating values on a PX-07-008 tester (Suzhou Phinix Instruments Co., Ltd., Suzhou, China) in accordance with the GB/T8627-2007.

\subsubsection{Fire Protection Tests}

Fire protection properties of the samples were assessed by the big panel method, cabinet method, tunnel method tests according to GB12441-2018 standard procedure. In cabinet method tests, the weight loss (the difference of the sample mass before and after the 
test), char index, and intumescent factor (the ratio of the thickness of the coatings after and before test) of the samples were determined. The char index was calculated by Formula (1):

$$
\text { Char index }=\frac{\sum_{i=1}^{n}\left(a_{i} b_{i} h_{i}\right)}{n}
$$

where: $a_{i}$ is defined as the char length $(\mathrm{cm}), b_{i}$ is defined as the char width $(\mathrm{cm}), h_{i}$ is defined as the char depth $(\mathrm{cm})$, and $n$ is the number of samples.

Tunnel method test was conducted using a SDF-2-type 2-foot flame tunnel instrument (Jiangning Analysis Instrument Company, Nanjing, China). The flame spread over the coating surface of the samples was evaluated when ignited under controlled conditions in a small tunnel, and the flame-spread rating (FSR) of the samples was calculated by Formula (2):

$$
F R S=\frac{L_{s}-L_{a}}{L_{r}-L_{a}}
$$

where: $L_{s}$ is the mean of five flame advance readings of samples $(\mathrm{mm}), L_{a}$ is the mean of five flame advance readings of asbestos board $(\mathrm{mm})$, and $L_{r}$ is the mean of five flame advance readings of oak board ( $\mathrm{mm}$ ).

\subsubsection{Cone Calorimeter Test}

The cone calorimeter test was conducted at a heat flux of $50 \mathrm{~kW} / \mathrm{m}^{2}$ in the aluminum foil following ISO 5660-2002 standard procedure.

\subsubsection{Thermogravimetric Analysis}

TG analysis was carried out at a heating rate of $10^{\circ} \mathrm{C} / \mathrm{min}$, and the samples were heated from $35{ }^{\circ} \mathrm{C}$ to $800{ }^{\circ} \mathrm{C}$ under a nitrogen atmosphere, using a TGA/SOTA 851 thermogravimetric instrument (Mettretoli Instruments Co., Ltd., Zurich, Switzerland). The theoretical char residue $\left(W_{\text {theo }}\right)$ of intumescent fire-retardant coating was calculated using Formula (3):

$$
W_{\text {theo }}(t)=\sum_{i=1}^{n} \chi_{i} W_{i}(t)
$$

where $\chi_{i}$ is the percent of compound $i, \%$; and $W_{i}(t)$ is the residual amount of char layer for compound $i$ at $t^{\circ} \mathrm{C}$.

\section{Results and Discussion}

\subsection{Morphology and Composition of Bio-Fillers}

The FTIR spectra of CES, CHS, and CMS are shown in Figure 1, and the FTIR assignments for the functional groups of different shell bio-fillers in Table 2. The characteristic peaks of shell bio-fillers are located at 700, 713, 859, 876, 1082, 1452, 1481, 1794, 2347, 2519, $2923,3422 \mathrm{~cm}^{-1}$, while the peaks at $1481,876,713 \mathrm{~cm}^{-1}$ are associated with the forms of calcite, and the peaks at $1425,1082,859,713,700 \mathrm{~cm}^{-1}$ are assigned to the forms of aragonite [15]. Due to the different vibrational modes of $\mathrm{CO}_{3}{ }^{2-}$, calcium carbonate with polymorphs can be accurately identified from the absorption peaks at 1481-1425, 1082, $876-859$, and $700-713 \mathrm{~cm}^{-1}$. The strong absorption peak at $1481 \mathrm{~cm}^{-1}$ originates from the asymmetric stretching of aragonite, while the asymmetric stretching vibration of calcite appears near $1425 \mathrm{~cm}^{-1}$. The C-O stretching vibration peak of aragonite is observed at $1082 \mathrm{~cm}^{-1}$, and the absorption peaks at 876 and $860 \mathrm{~cm}^{-1}$ are the out-of-plane deformation vibration peaks of $\mathrm{CO}_{3}{ }^{2-}$ for calcite and aragonite, respectively. The difference in the $\mathrm{O}-\mathrm{C}-\mathrm{O}$ bending frequency of aragonite and calcite is less than $2 \mathrm{~cm}^{-1}$, and these modes are recognized as a single absorption near $713 \mathrm{~cm}^{-1}$ in the spectra [16-20]. In conclusion, CES and CMS are composed of calcite $\mathrm{CaCO}_{3}$ and aragonite $\mathrm{CaCO}_{3}$, respectively, while CHS is a mixture of calcite and aragonite $\mathrm{CaCO}_{3}$. 


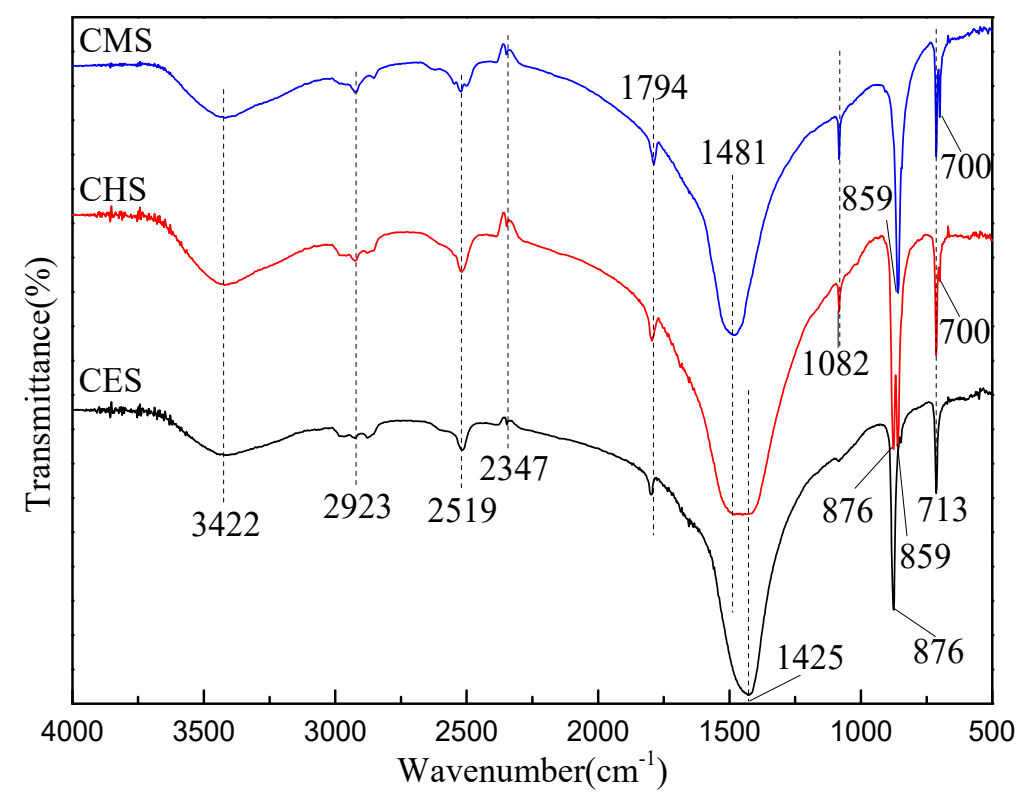

Figure 1. FTIR spectra of different shell bio-fillers.

Table 2. FTIR assignments for the functional groups of different shell bio-fillers.

\begin{tabular}{ccc}
\hline FTIR Band $\left(\mathbf{c m}^{-\mathbf{1}}\right)$ & Functional Groups & Intensity \\
\hline 3422 & $-\mathrm{OH}$ stretching [21] & Strong \\
2923 & $-\mathrm{CH}_{2}$ stretching [22] & Weak \\
2517,1794 & Organics & Strong \\
1481 & Asymmetric stretching of aragonite & Strong \\
1425 & Asymmetric stretching of calcite & Strong \\
1082 & $\mathrm{C}-\mathrm{O}$ stretching vibration peak of aragonite & Weak \\
876 & $\mathrm{CO}_{3}{ }^{2-}$ out-of-plane deformation vibration peak of calcite & Strong \\
859 & $\mathrm{CO}_{3}{ }^{2-}$ out-of-plane deformation vibration peak of aragonite & Strong \\
713 & O-C-O in-plane deformation vibration peak & Strong \\
700 & stretching of aragonite & Weak \\
\hline
\end{tabular}

The XRD patterns of the shell bio-fillers are shown in Figure 2. The XRD pattern of the CES bio-filler matches with the calcite $\left(\mathrm{CaCO}_{3}, \mathrm{PDF}\right.$ 86-2334) pattern and the main phases of the CHS powder are identified as calcite $\left(\mathrm{CaCO}_{3}, \mathrm{PDF} \# 86-0174\right)$ and aragonite phases $\left(\mathrm{CaCO}_{3}, \mathrm{PDF} \# 75-2230\right)$. The $\mathrm{CMS}$ belongs to a typical aragonite structure $\left(\mathrm{CaCO}_{3}\right.$, PDF\#71-2396) without any characteristic of the calcite phase. These results are confirmed by the results of FTIR spectra in Figure 2, which is also consistent with the previous reports $[7,8,19,23]$.
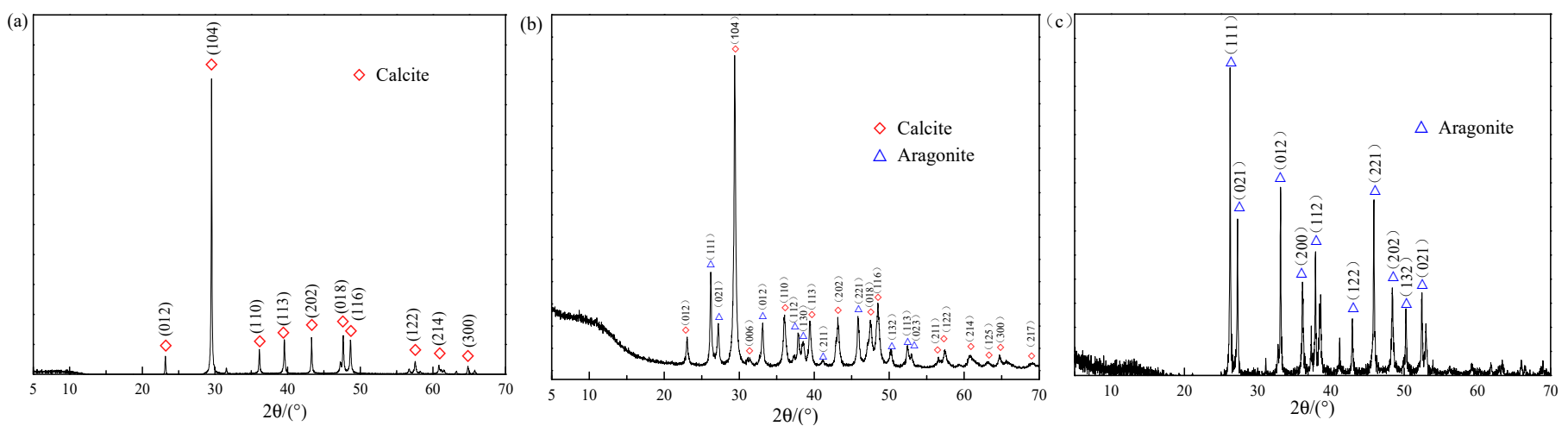

Figure 2. XRD patterns of shell bio-fillers. (a) CES; (b) CHS; (c) CMS. 
The morphologies and compositions of CES, CHS, and CMS are presented in Figure 3. As seen in Figure 3, all the bio-fillers show an irregular blocky structure with a rough surface, and the size is mainly distributed in the range of 1-20 $\mu \mathrm{m}$. By combining EDS results, it can be found that all the shell fillers mainly consist of $\mathrm{Ca}$, $\mathrm{O}$, and $\mathrm{C}$ elements, where there is a slight difference in content of Ca element.

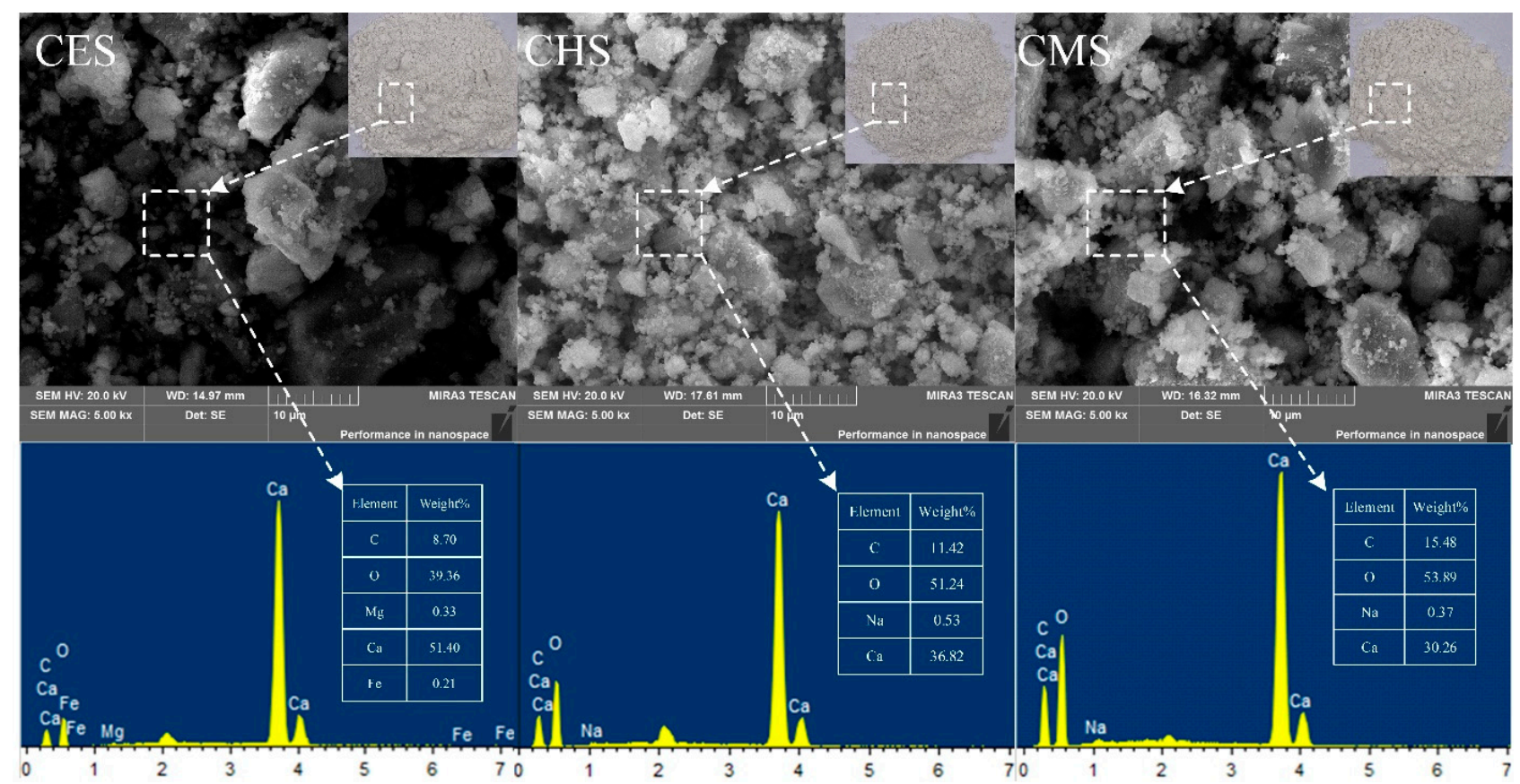

Figure 3. SEM images and EDS maps of shell bio-fillers.

The TG curves of CES, CHS, and CMS are shown in Figure 4. As observed from Figure 4, the pyrolysis process of shell bio-fillers is mainly divided in two stages in the temperature ranges of $100-550^{\circ} \mathrm{C}$ and $550-900^{\circ} \mathrm{C}$. The mass loss at $150-550{ }^{\circ} \mathrm{C}$ is attributed to the decomposition of organic matter, and the mass loss at $550-900{ }^{\circ} \mathrm{C}$ is assigned to the decomposition of calcium carbonate. Specifically, CES showed a higher mass loss at $150-550{ }^{\circ} \mathrm{C}$ due to the organic matter rich in CES. The char residues of CES, CHS, and CMS samples at $900{ }^{\circ} \mathrm{C}$ are $50.0 \%, 52.0 \%$, and $55.8 \%$, respectively, where CMS exerts the highest residual weight.

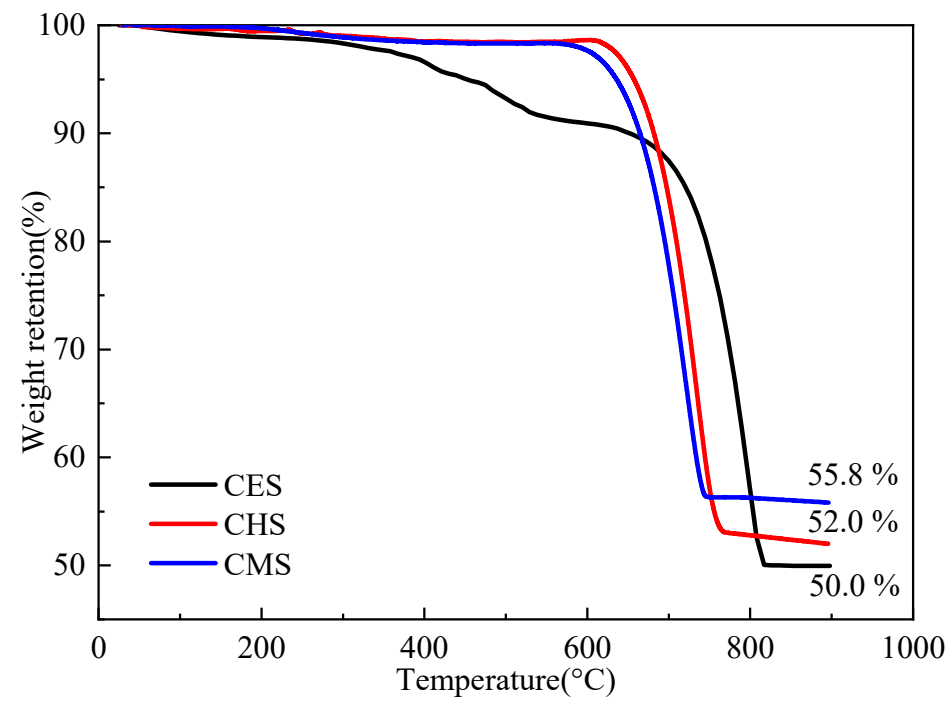

Figure 4. TG curves of shell bio-fillers. 


\subsection{Fire Protection Tests}

The tunnel method and cabinet method tests for the intumescent fire-retardant coatings applied in wood substrates are presented in Table 3. As seen in Table 3, the addition of shell bio-fillers exerts an excellent synergistic efficiency on enhancing the fire protection performance of intumescent fire-retardant coatings, among which the CMS shows the best synergistic effect. Especially, compared to IFRC-0 without bio-filler, the IFRC-CMS sample shows a $13.5 \%$ reduction in weight loss, $35.8 \%$ reduction in char index, $31.1 \%$ reduction in flame-spread rating, and 50.0\% increase in intumescent factor. The results indicate that the shell bio-fillers can effectively improve the fire resistance performance of intumescent fire-retardant coatings, and the synergistic effect of shell bio-filler depends on the polymorphs of $\mathrm{CaCO}_{3}$, in which the synergistic efficiency of aragonite $\mathrm{CaCO}_{3}$ is higher than that of calcite $\mathrm{CaCO}_{3}$.

Table 3. Fire protection performances of IFRCs.

\begin{tabular}{ccccc}
\hline Samples & IFRC-0 & IFRC-CES & IFRC-CHS & IFRC-CMS \\
\hline Weight loss $/ \mathrm{g}$ & $3.7 \pm 0.2$ & $3.4 \pm 0.1$ & $3.4 \pm 0.1$ & $3.2 \pm 0.3$ \\
Char index $/ \mathrm{cm}^{3}$ & $24.3 \pm 1.1$ & $19.6 \pm 2.6$ & $18.7 \pm 0.7$ & $15.6 \pm 1.1$ \\
Flame-spread rating & $20.9 \pm 3.3$ & $19.0 \pm 1.8$ & $15.0 \pm 4.6$ & $14.4 \pm 2.4$ \\
Intumescent factor & $30.0 \pm 4.1$ & $38.3 \pm 4.7$ & $41.7 \pm 2.4$ & $45.0 \pm 4.1$ \\
\hline
\end{tabular}

The results from the big panel method test for the intumescent fire-retardant coatings applied in wood substrates are illustrated in Figure 5. From Figure 5, the IFRC-0 without shell bio-filler exhibits a poor heat-insulation performance with a fire-resistant time of $700 \mathrm{~s}$. The presence of shell bio-fillers induces a significant slowdown in the rate of temperature rise during combustion, where the equilibrium backside temperatures of IFRC-CES, IFRCCHS, and IFRC-CMS are $179.3,163.9$, and $134.6^{\circ} \mathrm{C}$ at $900 \mathrm{~s}$, respectively. The results reveal that shell bio-filler can effectively improve the heat-insulation property of intumescent fire-retardant coatings, where IFRC-CMS with $3 \mathrm{wt} \%$ shell bio-filler performs the best synergistic flame-retardant effect. This is consistent with the results of the tunnel method and cabinet method tests.

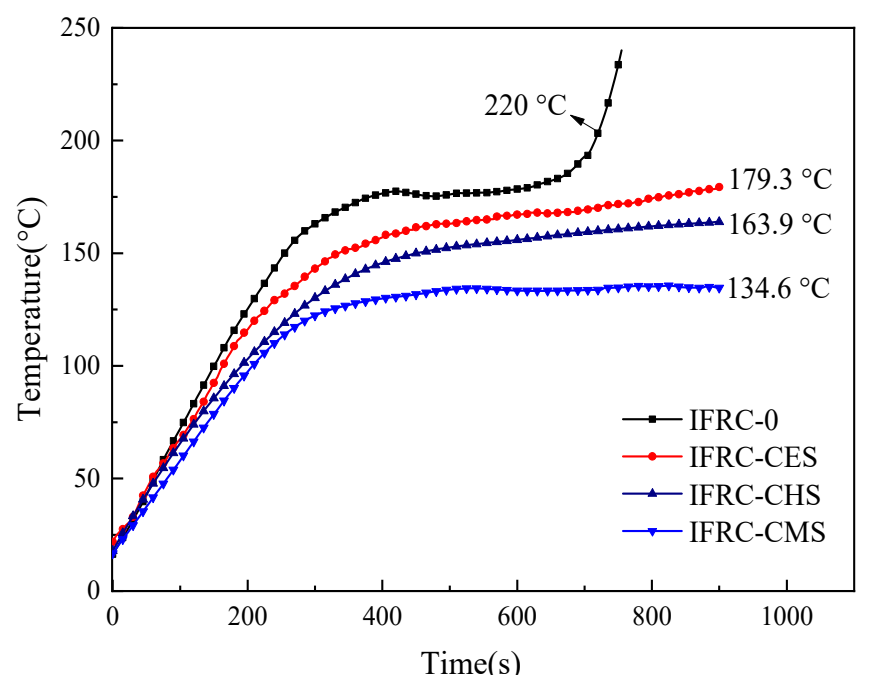

Figure 5. Backside temperature curves of IFRCs assessed by the big panel method test.

To further investigate the synergistic effect of shell bio-fillers with different polymorphs on intumescent fire-retardant coatings, the morphologies of the char layer were analyzed. As shown in Figure 6, the IFRC-0 sample without shell bio-filler shows a low expansion ratio and large charring area, corresponding to a weak heat-insulation property. After addition of shell bio-fillers, the coatings form a higher intumescent char, and the char 
height is $11.0,12.5$, and $14.0 \mathrm{~mm}$ for IFRC-CES, IFRC-CHS, and IFRC-CMS, respectively. This phenomenon implies that the addition of shell bio-fillers can promote the intumescent process of the char layer to block the transfer of heat and mass, while effectively inhibiting the decomposition of the underlying materials. The IFRC-CMS exhibits the best fire resistance properties among the samples, which is attributed to the fact that calcite $\mathrm{CaCO}_{3}$ has stronger adsorption for phosphate than aragonite $\mathrm{CaCO}_{3}$ that plays a negative effect on the intumescent process of the coatings [13]. By combing the results of SEM-EDS from Figure 7, the char layer with shell bio-fillers contains higher amounts of $\mathrm{P}$ and $\mathrm{Ca}$ elements, in which the IFRC-CMS presents the highest content. This phenomenon means that the shell bio-filler with aragonite can promote the formation of more phosphorus-rich and calcium-rich cross-linked structures in the char layer that improve the strength of the char layer. With the addition of same amount of bio-filler, the CMS is prone to endow the coating with excellent expansion and char-forming ability concomitant with superior fire resistance.

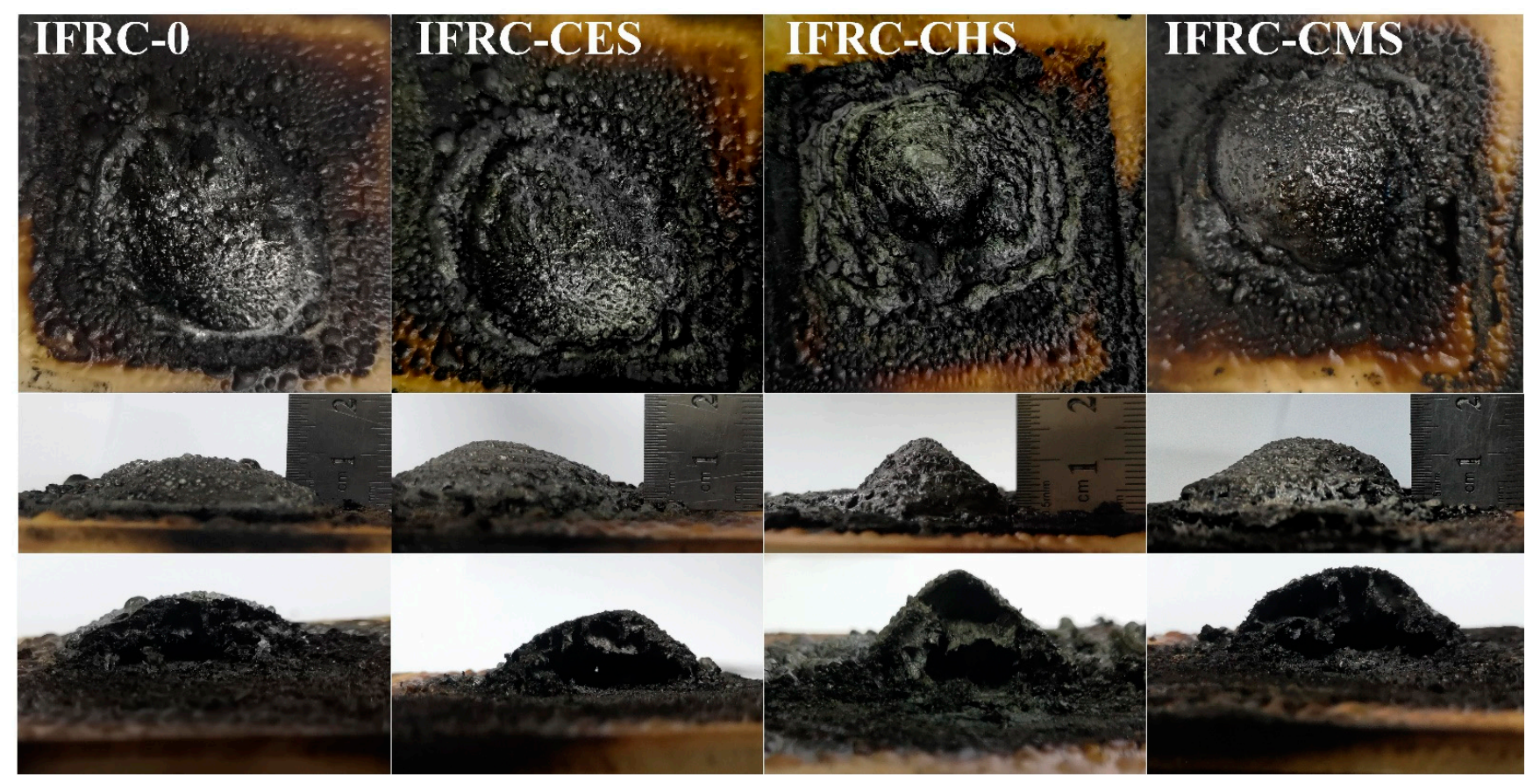

Figure 6. Photographs of the char residues obtained from the big panel method test.

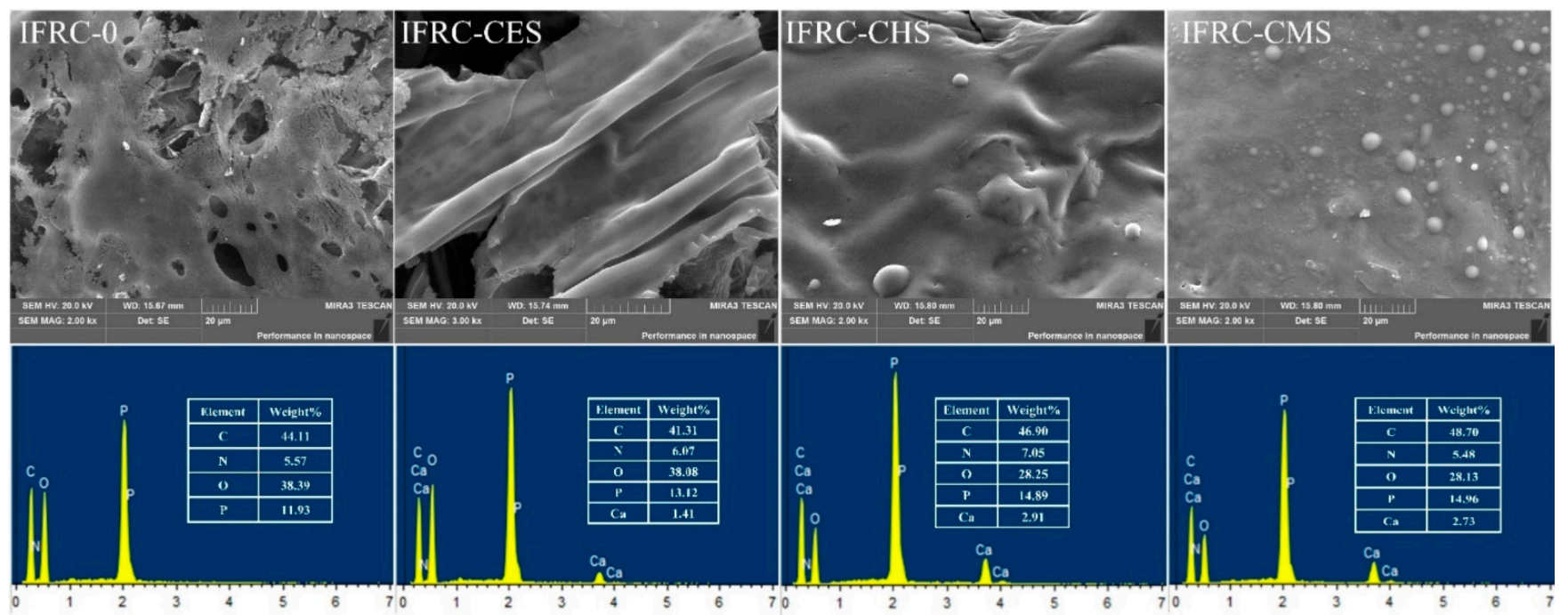

Figure 7. SEM images and EDS maps of the char residues obtained from the big panel method test. 


\subsection{Cone Calorimeter Test}

The cone calorimeter test is an effective way to evaluate the fire protection performance for the intumescent fire-retardant coatings applied in wood substrates, and the results are illustrated in Figure 8 and Table 4 . The peak heat release rate (PHRR) value and total heat release (THR) for the IFRC-0 are $94.0 \mathrm{~kW} / \mathrm{m}^{2}, 5.9 \mathrm{MJ} / \mathrm{m}^{2}$ respectively, and the addition of shell bio-fillers effectively reduces the THR and PHRR values of the coatings. Compared with IFRC-0, the PHRR and THR values are decreased by $7.2 \%$ and $16.9 \%$ for IFRC-CES, $18.8 \%$ and $27.1 \%$ for IFRC-CHS, $23.1 \%$ and $32.2 \%$ for IFRC-CMS, respectively, indicating that all the shell bio-fillers have a good synergistic efficiency in reducing the heat release. Among the samples, IFRC-CMS sample presents the lowest PHRR and THR values. However, the synergistic efficiency of bio-filler in the intumescent fire-retardant coatings depends on the polymorphs of the shell bio-fillers, and the synergistic efficiency of bio-filler is enhanced with the increase amount of aragonite $\mathrm{CaCO}_{3}$ in bio-filler. This phenomenon is ascribed to the fact that the shell bio-filler can react with the phosphoric acid derivatives released from APP to form thermally stable calcium metaphosphate and calcium phosphate on the surface of the char layer that effectively block the transfer of mass and heat, thus enhancing the fire resistance [24]. Nevertheless, calcite has stronger adsorption for phosphate than aragonite to cause the reduction of acid source [13], which suppresses the dehydration of carbon source, carbonization, and chain decomposition of the intumescent fire-retardant coatings, thus diminishing the expansion and char-forming rate of the char layer as well as the synergistic flame-retarded efficiency.
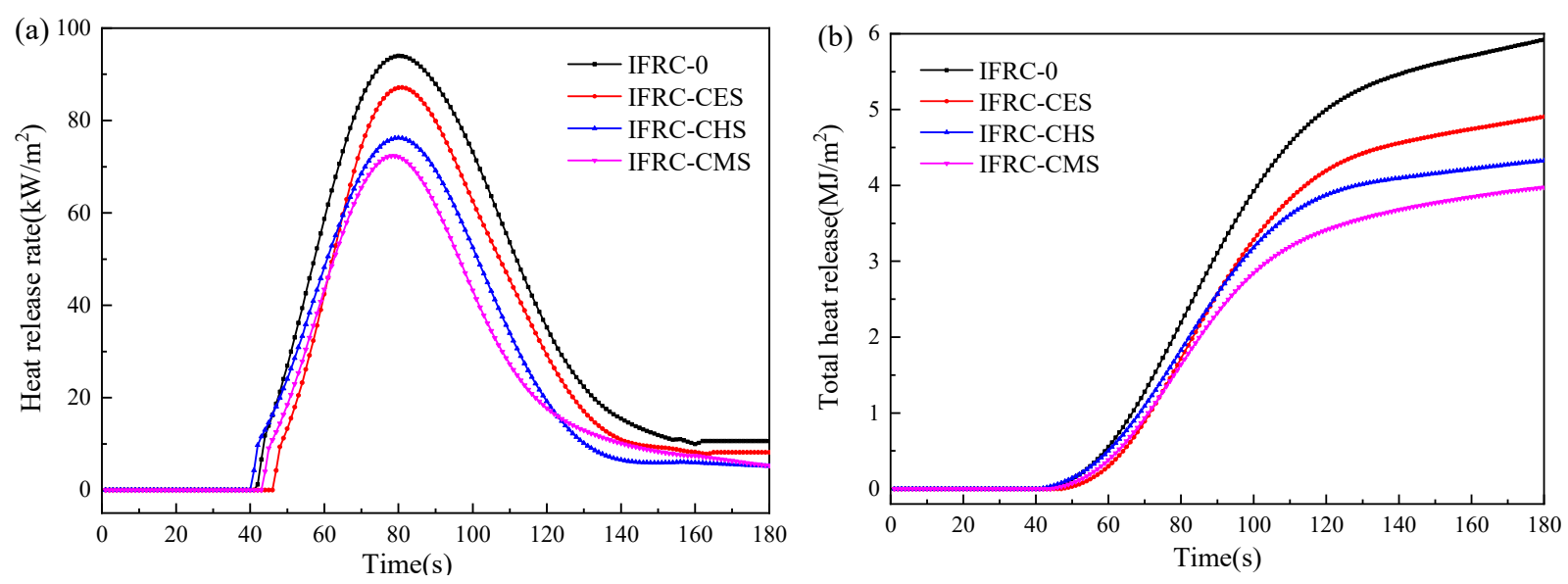

Figure 8. HRR (a) and THR (b) curves of IFRCs.

Table 4. Cone data of the intumescent fire-retardant coatings applied in wood substrate.

\begin{tabular}{cccccc}
\hline Samples & TTI/s & PHRR/(kW· $\mathbf{m}^{-\mathbf{2}} \mathbf{)}$ & Time to PHRR/s & THR/(MJ· $\left.\mathbf{m}^{-\mathbf{2}}\right)$ & Residue/\% \\
\hline IFRC-0 & 41 & 94.0 & 80 & 5.9 & 60.0 \\
IFRC-CES & 47 & 87.2 & 81 & 4.9 & 62.1 \\
IFRC-CHS & 41 & 76.3 & 80 & 4.3 & 62.7 \\
IFRC-CMS & 44 & 72.3 & 79 & 4.0 & 64.5 \\
\hline
\end{tabular}

\subsection{Smoke Density Test}

The smoke density rate (SDR) and light absorption curves for the intumescent fireretardant coatings applied in wood substrates are presented in Figure 9. The IFRC-0, IFRC-CES, IFRC-CHS, and IFRC-CMS show the maximum light absorption values of $64.3 \%, 54.6 \%, 53.2 \%$, and $46.8 \%$, respectively, and SDR values of $32.5 \%, 29.3 \%, 28.2 \%$, and $22.8 \%$, respectively. Compared to IFRC-0, the addition of shell bio-filler can effectively decrease the smoke density rating values and light absorption rate of intumescent fireretardant coatings. IFRC-CMS sample shows the lowest smoke density rating values 
and light absorption rate, which is ascribed to the formation of more residual weight, as supported by TG analysis.
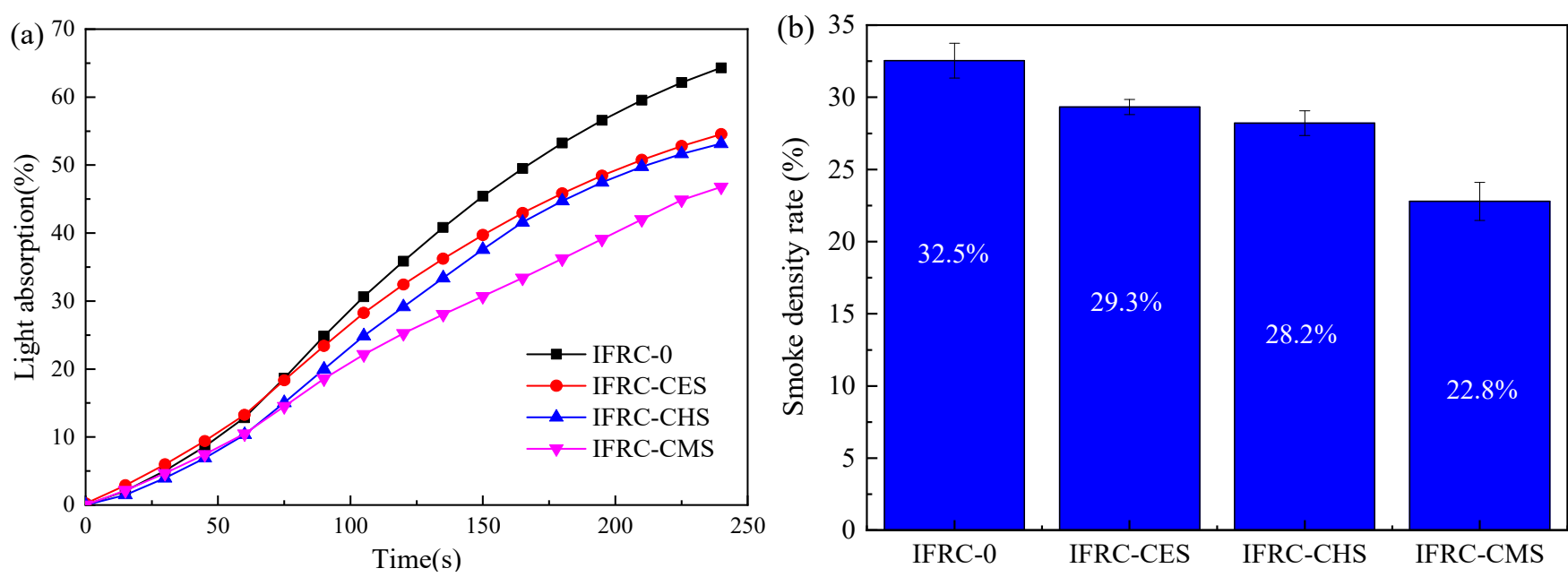

Figure 9. Light-absorptivity curves (a) and smoke density rate (b) of IFRCs.

\subsection{Thermal Stability Analysis}

The TG and DTG curves of the coatings are illustrated in Figure 10, and the thermal data is depicted in Table 5. From Figure 10, it can be observed that the pyrolysis process of intumescent fire-retardant coatings mainly occurs in the temperature ranges of $100-315{ }^{\circ} \mathrm{C}, 315-445^{\circ} \mathrm{C}$, and $445-600{ }^{\circ} \mathrm{C}$. The first stage at $100-315^{\circ} \mathrm{C}$ is mainly caused by the volatilization of small molecules from the waterborne epoxy resin and flame retardants, which results in more than $20 \%$ weight loss. The second stage at $315-445^{\circ} \mathrm{C}$ is ascribed to the interaction of MEL, PER, and APP to form an expanded char layer, in which APP will decompose to produce phosphoric acid to catalyze the esterification of PER into molten char, while MEL will generate a large amount of inert gas that promote the expansion of molten char to form intumescent char, effectively blocking the transfer of mass and heat. The third stage at $445-600^{\circ} \mathrm{C}$ is the reaction stage of the shell bio-filler with the phosphoric acid to form thermally stable calcium metaphosphate and calcium phosphate to enhance the thermal stability of char layer at high temperature. The IFRC-CMS sample acquires the highest residual weight of $37.4 \%$ at $800{ }^{\circ} \mathrm{C}$.

(a)

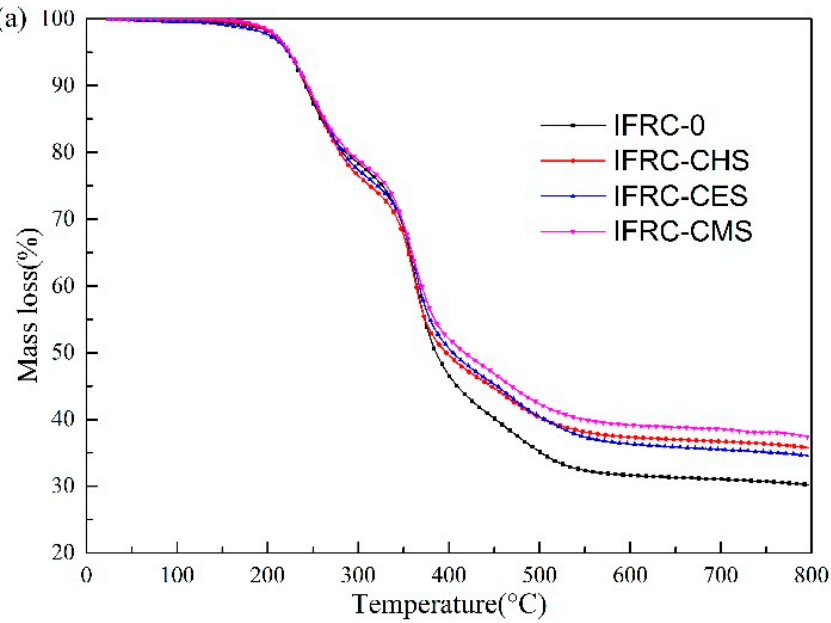

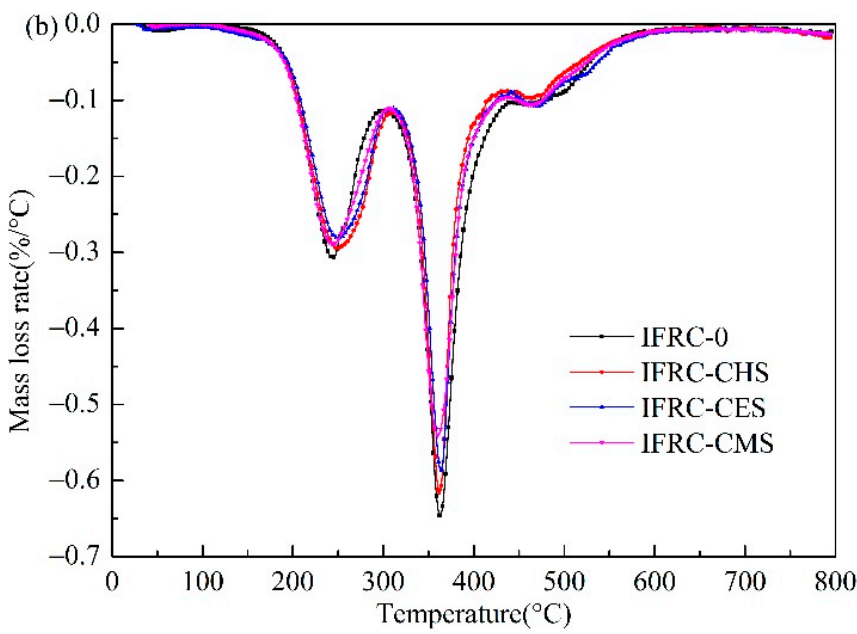

Figure 10. TG (a) and DTG (b) curves of IFRCs under nitrogen atmosphere. 
Table 5. Thermal data of the IFRCs under nitrogen atmosphere.

\begin{tabular}{|c|c|c|c|c|c|c|c|c|c|c|}
\hline \multirow{2}{*}{ Samples } & \multirow{2}{*}{$T_{0} /{ }^{\circ} \mathrm{C}$} & \multirow{2}{*}{$T_{\mathrm{m}} /{ }^{\circ} \mathrm{C}$} & \multirow{2}{*}{$\begin{array}{l}\text { PMLR/ } \\
\left(\% /{ }^{\circ} \mathrm{C}\right)\end{array}$} & \multicolumn{4}{|c|}{ Weight Loss/\% } & \multirow{2}{*}{$\begin{array}{c}W_{\exp } \\
\left(8000^{\circ} \mathrm{C}\right) / \%\end{array}$} & \multirow{2}{*}{$\begin{array}{c}W_{\text {theo }} \\
\left(800^{\circ} \mathrm{C}\right) / \%\end{array}$} & \multirow{2}{*}{$\begin{array}{c}\Delta W \\
\left(800^{\circ} \mathrm{C}\right) / \%\end{array}$} \\
\hline & & & & $100 \sim 315^{\circ} \mathrm{C}$ & $315 \sim 445^{\circ} \mathrm{C}$ & $445 \sim 600{ }^{\circ} \mathrm{C}$ & $600 \sim 800^{\circ} \mathrm{C}$ & & & \\
\hline IFRC-0 & 223.0 & 362.9 & 0.6 & 23.0 & 36.0 & 9.3 & 1.4 & 30.2 & 16.8 & 13.4 \\
\hline IFRC-CES & 222.6 & 363.2 & 0.6 & 23.9 & 30.0 & 9.4 & 1.7 & 34.6 & 17.6 & 17.0 \\
\hline IFRC-CHS & 223.7 & 362.0 & 0.6 & 25.2 & 30.1 & 7.3 & 1.6 & 35.8 & 17.5 & 18.3 \\
\hline IFRC-CMS & 224.1 & 360.4 & 0.5 & 22.8 & 29.9 & 8.2 & 1.7 & 37.4 & 17.7 & 19.7 \\
\hline
\end{tabular}

Notes: $T_{0}$, initial decomposition temperature, which was the temperature when the mass loss was up to $5 \%$; PMLR, the peak of mass loss rate; $\Delta W=W_{\text {exp }}-W_{\text {theo }} ; W_{\text {exp }}$ of the waterborne epoxy resin, IFR, CES, CHS, CMS at $800{ }^{\circ} \mathrm{C}$ were $6.7 \%, 25.2 \%, 50.0 \%, 52.0 \%$, $55.8 \%$, respectively.

As shown in Table 5, the addition of CES causes a decrease in the initial decomposition temperature $\left(T_{0}\right)$ and an increase in the temperature of peak mass loss rate $\left(T_{\mathrm{m}}\right)$, while the addition of CHS and CMS leads the coating to show the opposite trends. However, there is no obvious differences in $T_{0}$ and $T_{\mathrm{m}}$ caused by CES, CHS, and CMS. In addition, the experimental residual weight ( $W_{\text {exp }}$ ) of IFRC-0, IFRC-CES, IFRC-CHS, and IFRC-CMS coatings, which are $30.2 \%, 34.6 \%, 35.8 \%$, and $37.4 \%$ respectively, are significantly higher than the corresponding theoretical residual weight $\left(W_{\text {theo }}\right)$. This results reveal that the existence of interaction among the waterborne epoxy resin, intumescent flame retardant and shell bio-fillers, and the IFRC-CMS has a maximum $\Delta W$ of $19.7 \%$ [24]. This phenomenon may be attributed to the fact that shell bio-fillers can react with phosphoric acid to form stable calcium metaphosphate and calcium phosphate to enhance the strength of the char layer. However, the presence of calcite $\mathrm{CaCO}_{3}$ will reduce the synergistic efficiency of bio-fillers due to the strong adsorption between calcite and phosphate, as supported by Liu [13]. The above results show that the presence of shell bio-filler can effectively improve the expansion and char-forming ability of intumescent fire-retardant coatings, in which CMS composed of aragonite $\mathrm{CaCO}_{3}$ exerts excellent synergistic efficiency.

\subsection{Fire Resistance and Char Formation Mechanism}

To further investigate the synergistic fire resistance and char formation mechanism of shell bio-fillers in intumescent coatings, the coatings were heated in a muffle furnace under different temperatures, and the photographs of the char layer are presented in Figure 11. When the temperature increases to $200{ }^{\circ} \mathrm{C}$, the coatings transfer to yellow sample and occur expansion phenomenon. When the temperature rises to $300^{\circ} \mathrm{C}$, the coatings start to carbonize, where the IFRC-CMS presents a better expansion. When the temperature reaches $400^{\circ} \mathrm{C}$, MEL PER, and APP interact to form an expanding char layer, among which IFRC-CMS has the optimal expansion and char formation. As the temperature continues to rise, the char layer begins to decompose, and IFRC-CMS coating has the highest residual weight at $800^{\circ} \mathrm{C}$.

Figure 12 shows the FTIR spectra of coatings under different treatment temperatures, and the assignments of characteristic groups are listed Table 6. As can be seen from Figure 12, when the temperature is up to $300{ }^{\circ} \mathrm{C}$, the absorption peaks of $-\mathrm{NH}_{2}(3470$, $\left.3420 \mathrm{~cm}^{-1}\right),-\mathrm{CH}_{2}\left(2956,2886 \mathrm{~cm}^{-1}\right), \mathrm{N}-\mathrm{H}\left(1553,3136 \mathrm{~cm}^{-1}\right), \mathrm{PO}_{3}{ }^{2-}\left(1128 \mathrm{~cm}^{-1}\right), \mathrm{C}-\mathrm{O}$ $\left(1016 \mathrm{~cm}^{-1}\right)$, and $\mathrm{P}-\mathrm{O}-\mathrm{P}\left(874,674 \mathrm{~cm}^{-1}\right)$ functional groups disappear, and a new stretching vibrational peak appears at $1045 \mathrm{~cm}^{-1}$ assigned to $\mathrm{P}-\mathrm{O}-\mathrm{C}$ group [25-34], indicating that APP decomposes to phosphoric acid derivatives that catalyze PER esterification into carbon. When the temperature reaches $400{ }^{\circ} \mathrm{C}$, the absorption peaks of the main functional groups for the original coating have basically disappeared, indicating that the coatings have degraded or engaged in the carbonization reaction to form intumescent char via the interaction of APP, PER, and MEL. As the temperature continues to increase, the formed expanded char layer starts to decompose. Compared with IFRC-0, the samples containing shell bio-fillers exhibit stronger absorption peaks of $\mathrm{P}=\mathrm{O}\left(1286 \mathrm{~cm}^{-1}\right), \mathrm{C}-\mathrm{O}-\mathrm{C}\left(1127 \mathrm{~cm}^{-1}\right)$, $\mathrm{P}-\mathrm{O}-\mathrm{C}\left(1017,944 \mathrm{~cm}^{-1}\right)$, and $\mathrm{C}-\mathrm{H}\left(758,738 \mathrm{~cm}^{-1}\right)$ functional groups [35-39], indicating that the presence of bio-fillers can induce the formation of more aromatic structures and phosphorus-rich cross-linked structures. In general, the presence of these cross-linked and 
aromatic structures can improve the thermal stability of the expanded char layer, thus expressing a higher amount of char residue in Figure 11.

The fire resistance and char formation mechanism of shell bio-fillers in intumescent fire-retardant coatings are depicted in Figure 13. As seen in Figure 13, APP decomposes to generate phosphoric acid, metaphosphoric acid, and non-combustible gas, where phosphoric acid and metaphosphoric acid will catalyze the esterification of PER into molten char. In this stage, the bio-fillers can react with phosphoric acid and metaphosphoric acid to form stable calcium metaphosphate and calcium phosphate that enhances the strength and compactness of the char layer. With the increase of temperature, MEL will cyclize and decompose into triazine compounds concomitant with the release of a large amount of non-combustible gas that promotes the expansion of the char layer and dilutes the fuel gases to reduce the intensity of combustion. The synergistic efficiency of bio-fillers depends on the polymorphs of shell bio-fillers, and aragonite $\mathrm{CaCO}_{3}$ shows higher synergistic efficiency than calcite $\mathrm{CaCO}_{3}$, which is attributed to the fact that calcite $\mathrm{CaCO}_{3}$ has stronger adsorption for phosphate than aragonite $\mathrm{CaCO}_{3}$ that plays a negative effect on the intumescent process of the coatings. Compared to calcite $\mathrm{CaCO}_{3}$, aragonite $\mathrm{CaCO}_{3}$ has a lower mass loss to coatings, effectively reducing the amount of heat release and smoke generation. Therefore, the addition of CMS exhibits excellent synergistic efficiency in improving the fire resistance and char-forming property. The CMS shows the highest synergistic efficiency in the intumescent coating with the same content, CHS comes second, and CES shows the least effect.

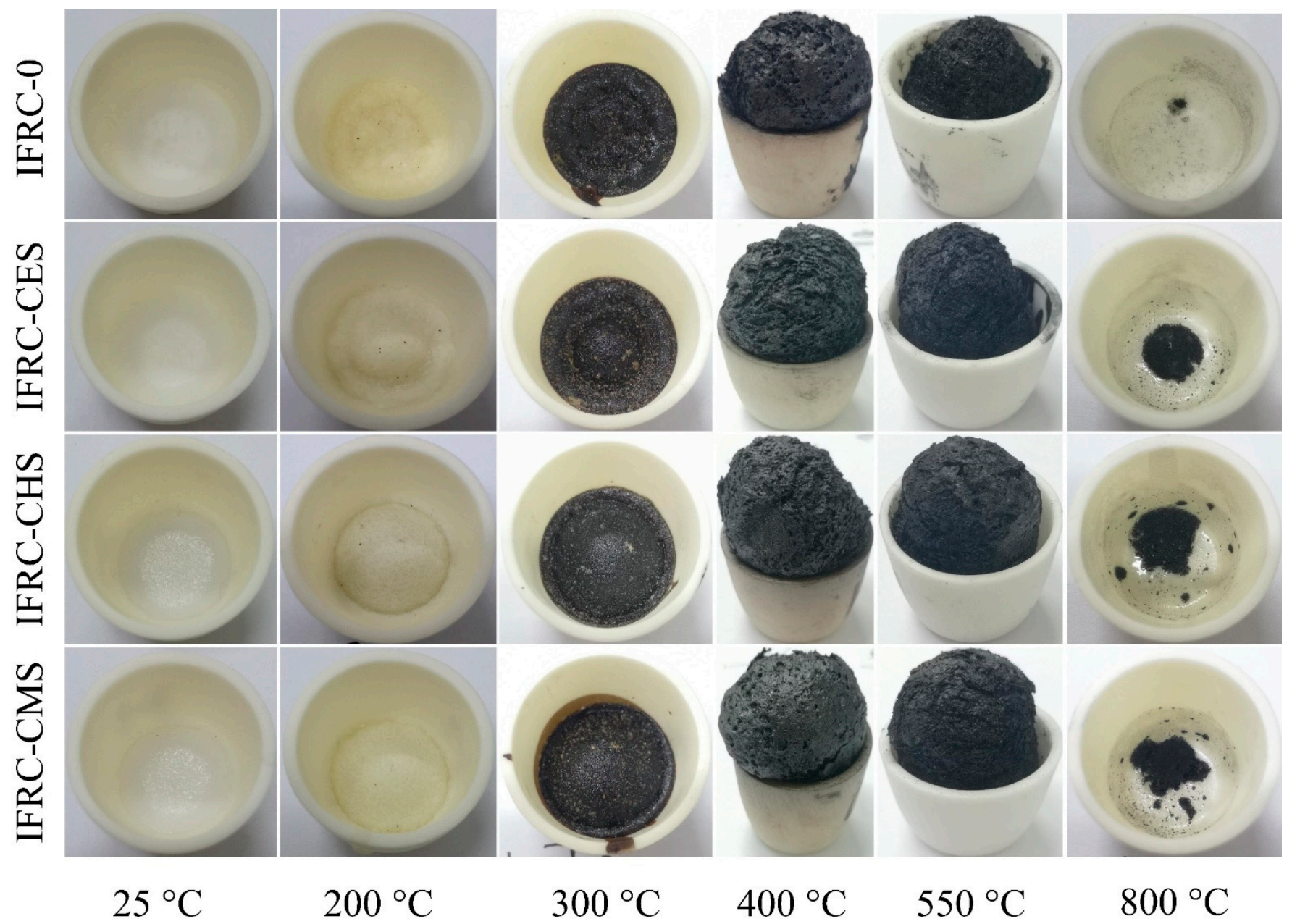

Figure 11. Photographs of char residues for IFRCs under different treatment temperatures. 
(a)

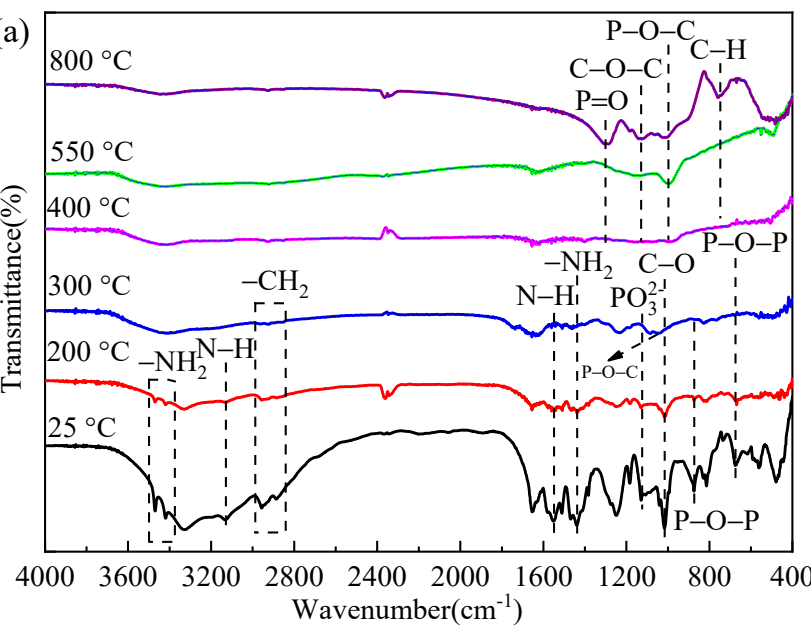

(d)

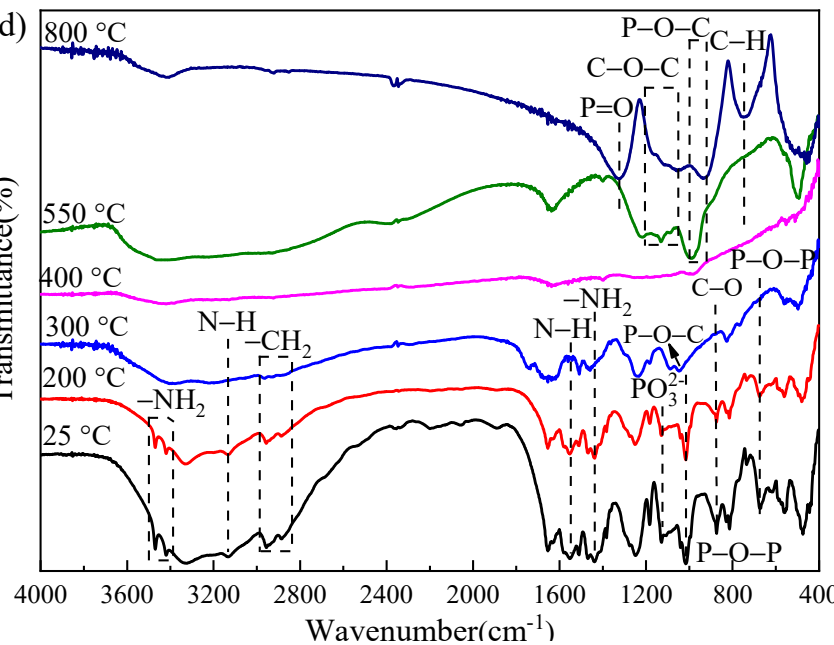

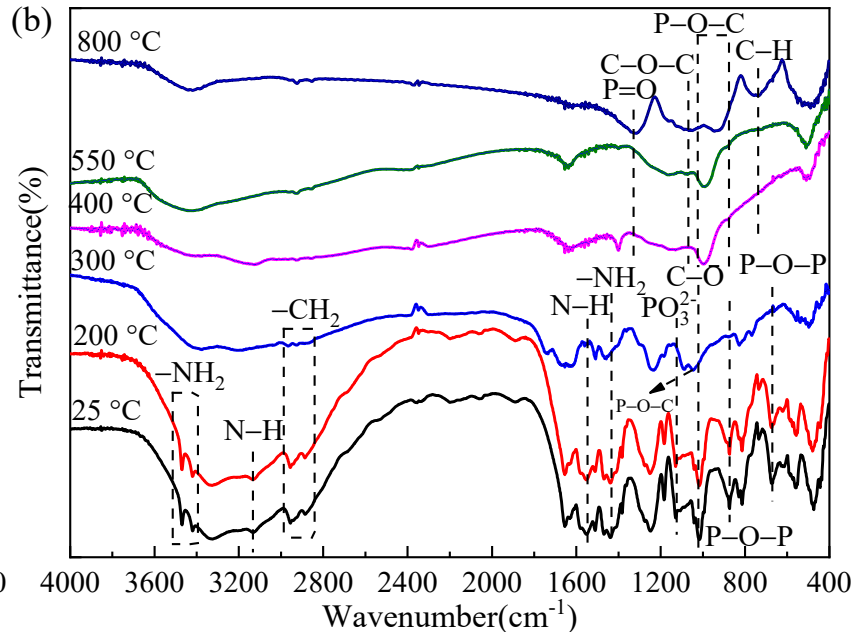

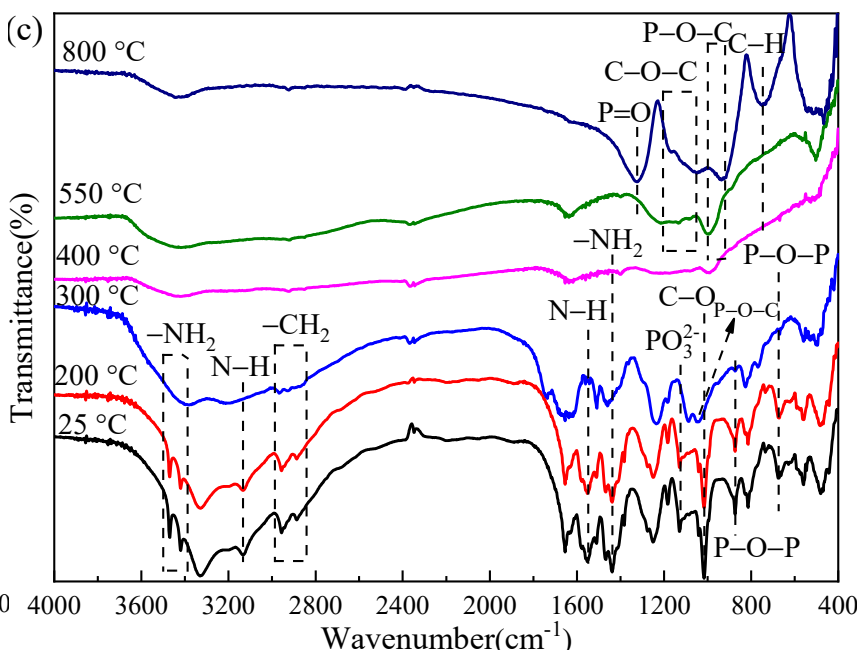

Figure 12. FTIR spectrum of intumescent fire-retardant Coatings under different treatment temperatures. (a) IFRC-0; (b) IFRC-CES; (c) IFRC-CHS; (d) IFRC-CMS.

Table 6. FTIR assignments for the functional groups of the IFRCs under different treatment temperatures.

\begin{tabular}{cccc}
\hline \multirow{2}{*}{ FTIR Band (cm $\left.\mathbf{c}^{-\mathbf{1}}\right)$} & Functional Groups & \multicolumn{2}{c}{ Observations } \\
\cline { 3 - 4 } & & Intensity & Changes \\
\hline 3470,3420 & $-\mathrm{NH}_{2}$ stretching & Strong & Disappeared \\
2956,2886 & $-\mathrm{CH}_{2}$ stretching & Strong & Disappeared \\
1552,3136 & $\mathrm{~N}-\mathrm{H}$ stretching & Strong & Disappeared \\
1286 & $\mathrm{P}=\mathrm{O}$ stretching & Strong & New, increased \\
1127 & $\mathrm{C}-\mathrm{O}-\mathrm{C}$ stretching & Strong & New, increased \\
1128 & $\mathrm{PO}_{3}^{2-}$ stretching & Strong & Disappeared \\
$1045,1017,944$, & $\mathrm{P}-\mathrm{O}-\mathrm{C}$ stretching & Strong & New, increased \\
1016 & $\mathrm{C}-\mathrm{O}$ stretching & Strong & Disappeared \\
758,738 & $\mathrm{C}-\mathrm{H}$ deformation for & Strong & New, increased \\
674,874 & benzene ring & Strong & Disappeared \\
\hline
\end{tabular}




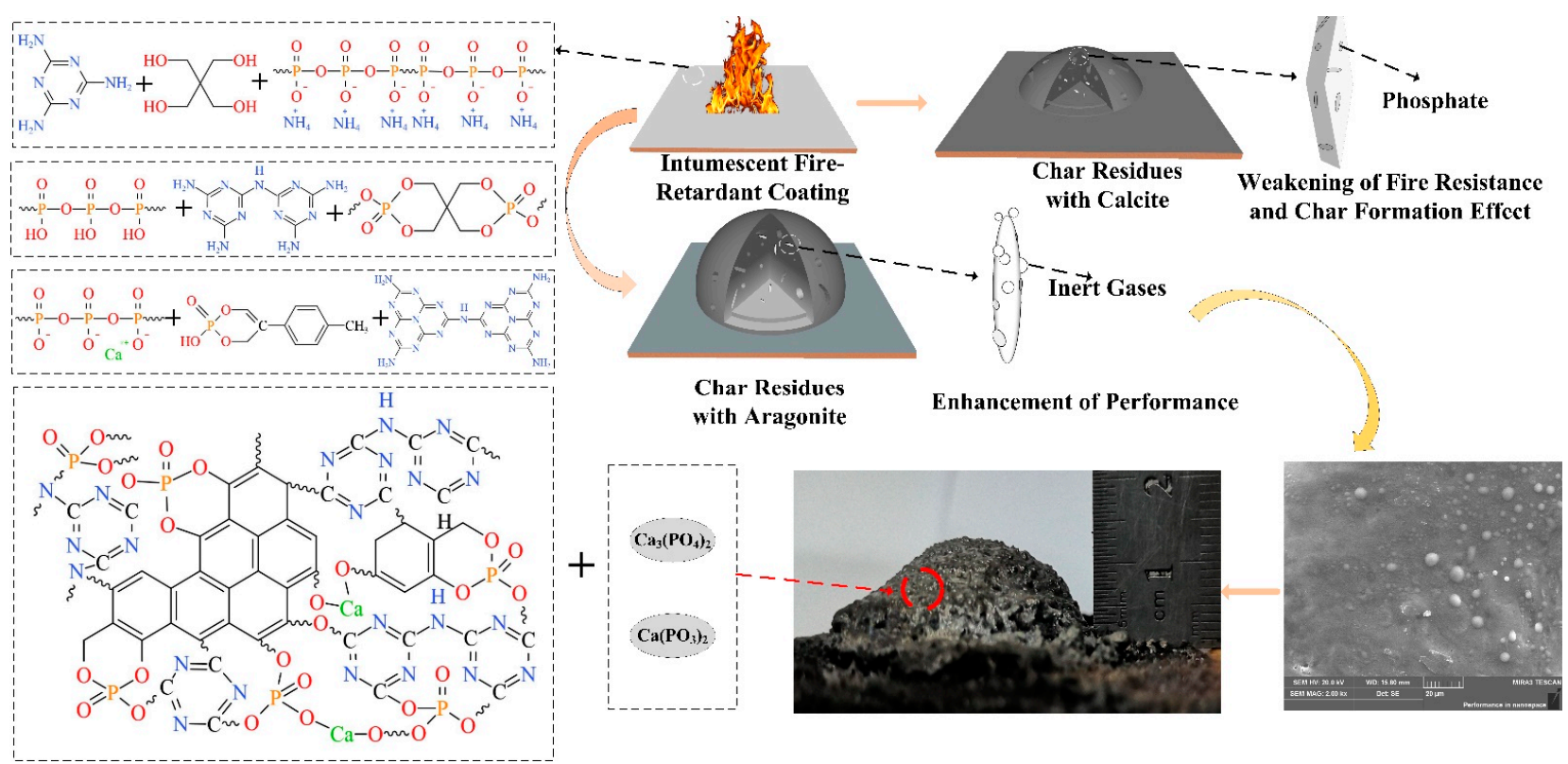

Figure 13. Fire resistance and char-forming mechanism of the different shell bio-fillers.

\section{Conclusions}

In this paper, three kinds of shell bio-fillers were prepared from eggshell, conch shell, and clamshell, respectively, and carefully characterized by FTIR, XRD, SEM, and TG analyses. Then, the obtained bio-fillers were applied to intumescent fire-retardant coatings as synergists, and the effects of shell bio-fillers on the fire resistance and char formation of intumescent fire-retardant coatings were investigated by different analytical methods. TG analysis indicates that the addition of shell bio-fillers can enhance the char-forming ability of the coatings, and the residual weights of IFRC-0, IFRC-CES, IFRC-CHS, and IFRC-CMS at $800{ }^{\circ} \mathrm{C}$ are $30.2 \%, 34.6 \%, 35.8 \%$, and $37.4 \%$, respectively. The fire protection tests show that the bio-fillers have an excellent synergistic effect on enhancing the fire resistance and char-forming properties of the intumescent fire-retardant coatings, in which CMS exerts the highest synergistic flame-retardant efficiency. The synergistic efficiency of shell bio-fillers in the intumescent coatings varies with the polymorphs of bio-fillers, and aragonite $\mathrm{CaCO}_{3}$ shows a better synergistic efficiency than that of calcite $\mathrm{CaCO}_{3}$. When the same content of bio-filler is added, CMS consisting of aragonite $\mathrm{CaCO}_{3}$ shows the highest synergistic efficiency, $\mathrm{CHS}$ composed of the mixture of aragonite $\mathrm{CaCO}_{3}$ and calcite $\mathrm{CaCO}_{3}$ comes second, and CES composed of calcite $\mathrm{CaCO}_{3}$ shows the least effect. Especially, IFRC-CMS coating containing CMS shows the best fire resistance and smoke suppression property, which exhibits a $13.5 \%$ reduction in weight loss, $35.8 \%$ reduction in char index, $31.1 \%$ reduction in flame-spread rating, 32.2\% reduction in total heat release, and $29.8 \%$ reduction in smoke density rate compared to IFRC-0 coating without bio-filler. Compared to calcite $\mathrm{CaCO}_{3}$, aragonite $\mathrm{CaCO}_{3}$ has a lower mass loss to coatings, effectively reducing the amount of heat release and smoke generation. The above results show that the aragonite $\mathrm{CaCO}_{3}$ of shell bio-fillers is an effective synergist in enhancing the fire resistance and char-forming properties of the intumescent fire-retardant coatings.

Author Contributions: F.W., formal analysis, conception, writing-review and editing; H.L., investigation, methodology, validation, resources, data curation, writing-original draft preparation; L.Y., methodology, validation, writing - review and editing, project administration, supervision. All authors have read and agreed to the published version of the manuscript.

Funding: This study received funding from the National Natural Science Foundation of China (No. 51906261), the Key Research and Development Program of Hunan Province (No. 2020SK2057) and the Graduate Research and Innovation Project of Central South University (2020zzts636). 
Institutional Review Board Statement: Not applicable.

Informed Consent Statement: Not applicable.

Data Availability Statement: The data presented in this study are available upon request from the corresponding author.

Conflicts of Interest: The authors declare no conflict of interest.

\section{References}

1. Xu, Z.; Xie, X.; Yan, L.; Feng, Y. Fabrication of organophosphate-grafted kaolinite and its effect on the fire-resistant and anti-ageing properties of amino transparent fire-retardant coatings. Polym. Degrad. Stab. 2021, 188, 109589. [CrossRef]

2. Hou, W.; Zhang, G.; He, S. Fire Resistance Tests on Prestressed Box Girder with Intumescent Fire-Retardant Coatings. Fire Technol. 2021. [CrossRef]

3. Puri, R.; Khanna, A. Intumescent coatings: A review on recent progress. J. Coat. Technol. Res. 2017, 14, 1-20. [CrossRef]

4. Xu, Z.; Zhou, H.; Yan, L.; Jia, H. Comparative study of the fire protection performance and thermal stability of intumescent fire-retardant coatings filled with three types of clay nano-fillers. Fire Mater. 2019, 44, 112-120. [CrossRef]

5. Yan, L.; Xu, Z.; Liu, D. Synthesis and application of novel magnesium phosphate ester flame retardants for transparent intumescent fire-retardant coatings applied on wood substrates. Prog. Org. Coat. 2019, 129, 327-337. [CrossRef]

6. Prabhakar, M.; Shah, A.; Rao, K.; Song, J. Mechanical and thermal properties of epoxy composites reinforced with waste peanut shell powder as a bio-filler. Fibers Polym. 2015, 16, 1119-1124. [CrossRef]

7. Wang, F.; Liu, H.; Yan, L.; Feng, Y. Comparative Study of Fire Resistance and Anti-Ageing Properties of Intumescent Fire-Retardant Coatings Reinforced with Conch Shell Bio-Filler. Polymers 2021, 13, 2620. [CrossRef] [PubMed]

8. Li, Y.; Feng, Y.; Xu, Z.; Yan, L.; Xie, X.; Wang, Z. Synergistic effect of clam shell bio-filler on the fire-resistance and char formation of intumescent fire-retardant coatings. J. Mater. Res. Technol. 2020, 9, 14718-14728. [CrossRef]

9. Jing, Y.; Nai, X.; Dang, L.; Zhu, D.; Wang, Y.; Dong, Y.; Li, W. Reinforcing polypropylene with calcium carbonate of different morphologies and polymorphs. Sci. Eng. Compos. Mater. 2018, 25, 745-751. [CrossRef]

10. Zhou, S.; Li, S.; Cao, X.; Qian, Y.; Li, L.; Chen, X. Combustion behavior and thermal stability of ethylene-vinyl acetate composites based on $\mathrm{CaCO}_{3}$-containing oil sludge and carbon black. J. Therm. Anal. Calorim. 2019, 136, 1135-1145. [CrossRef]

11. Zhang, M.; Li, J.; Zhao, J.; Cui, Y.; Luo, X. Comparison of $\mathrm{CH}_{4}$ and $\mathrm{CO}_{2}$ Adsorptions onto Calcite(10.4), Aragonite(011)Ca, and Vaterite(010) $\mathrm{CO}_{3}$ Surfaces: An MD and DFT Investigation. ACS Omega 2020, 5, 11369-11377. [CrossRef] [PubMed]

12. Radek, Š.; Petra, M.; Marta, P.; Alberto, V. Influence of additions of synthetic anhydrous calcium carbonate polymorphs on nanolime carbonation. Constr. Build. Mater. 2019, 228, 116802. [CrossRef]

13. Liu, Q.; Guo, L.; Zhou, Y.; Dai, Y.; Feng, L.; Zhou, J.; Zhao, J.; Liu, J.; Qian, G. Phosphate adsorption on biogenetic calcium carbonate minerals: Effect of a crystalline phase. Desalination Water Treat. 2012, 47, 78-85. [CrossRef]

14. Li, L.; Gao, D.; Li, Z.; Cao, M.; Gao, J.; Zhang, Z. Effect of high temperature on morphologies of fibers and mechanical properties of multi-scale fiber reinforced cement-based composites. Constr. Build. Mater. 2020, 261, 120487. [CrossRef]

15. Khalil, H.; Chong, E.; Owolabi, F.; Asniza, M.; Tye, Y.; Tajarudin, H.; Paridah, M.; Rizal, S. Microbial-induced CaCO 3 filled seaweed-based film for green plasticulture application. J. Clean. Prod. 2018, 199, 150-163. [CrossRef]

16. Ashokan, A.; Rajendran, V.; Kumar, T.S.; Jayaraman, G. Eggshell derived hydroxyapatite microspheres for chromatographic applications by a novel dissolution-precipitation method. Ceram. Int. 2021, 47, 18575-18583. [CrossRef]

17. Trentini, A.; Biron, D.; Duarte, J.; Santos, V. Polyurethane membranes reinforced with calcium carbonate and oyster powder for application in the separation of $\mathrm{CH}_{4} / \mathrm{CO}_{2}$ from greenhouse gases. Braz. J. Chem. Eng. 2021, 38, 585-603. [CrossRef]

18. Chervonnyi, A.; Chervonnaya, A.; Chukanov, N. Effect of $\mathrm{CaCO}_{3}$ Polymorphs on the Strength of a Calcium Aluminosilicate Composite. Inorg. Mater. 2003, 39, 469-475. [CrossRef]

19. Islam, K.; Bakar, M.; Noordin, M.; Hussein, M.; Rahman, N.; Ali, M. Characterisation of calcium carbonate and its polymorphs from cockle shells (Anadara granosa). Powder Technol. 2011, 213, 188-191. [CrossRef]

20. Francesca, C.; Giovanni, C.; Anna, G.; Vincenzo, M. Low-temperature synthesis of nanometric apatite from biogenic sources. Ceram. Int. 2020, 46, 23526-23533. [CrossRef]

21. Hong, L.; Hu, X.; Rao, W.; Zhang, X. Flame retardancy and crack resistance of transparent intumescent fire-resistive coatings. J. Appl. Polym. Sci. 2015, 132, 137-180. [CrossRef]

22. Wang, P.; Yang, F.; Cai, Z. Synergistic effect of organo-montmorillonite and DOPO-based oligomer on improving the flame retardancy of epoxy thermoset. J. Therm. Anal. Calorim. 2017, 128, 1429-1441. [CrossRef]

23. Matej, B.; Anna, Z.; Martin, F.; Vladimír, G.; Jaroslav, B. Eggshell biomaterial: Characterization of nanophase and polymorphs after mechanical activation. Adv. Powder Technol. 2015, 26, 1597-1608. [CrossRef]

24. Xu, Z.; Chu, Z.; Yan, L.; Chen, H.; Jia, H.; Tang, W. Effect of chicken eggshell on the flame-retardant and smoke suppression properties of an epoxy-based traditional APP-PER-MEL system. Polym. Compos. 2019, 40, 2712-2723. [CrossRef]

25. Wang, J.; Wang, G. Influences of montmorillonite on fire protection, water and corrosion resistance of waterborne intumescent fire retardant coating for steel structure. Surf. Coat. Technol. 2014, 239, 177-184. [CrossRef]

26. Wang, J.; Zhao, M. Study on the effects of aging by accelerated weathering on the intumescent fire retardant coating for steel elements. Eng. Fail. Anal. 2020, 118, 104920. [CrossRef] 
27. Shi, Y.; Wang, G. The novel epoxy/PEPA phosphate flame retardants: Synthesis, characterization and application in transparent intumescent fire resistant coatings. Prog. Org. Coat. 2016, 97, 1-9. [CrossRef]

28. Zhu, F.; Xin, Q.; Feng, Q.; Liu, R.; Li, K. Influence of nano-silica on flame resistance behavior of intumescent flame retardant cellulosic textiles: Remarkable synergistic effect? Surf. Coat. Technol. 2016, 294, 90-94. [CrossRef]

29. Das, S.; Pandey, P.; Mohanty, S.; Nayak, S. Effect of nanosilica on the physicochemical, morphological and curing characteristics of transesterified castor oil based polyurethane coatings-ScienceDirect. Prog. Org. Coat. 2016, 97, 233-243. [CrossRef]

30. Gómez-Fernández, S.; Ugarte, L.; Peña-Rodriguez, C.; Corcuera, M.; Eceiza, A. The effect of phosphorus containing polyol and layered double hydroxides on the properties of a castor oil based flexible polyurethane foam. Polym. Degrad. Stab. 2016, 132, 41-51. [CrossRef]

31. Makhlouf, G.; Hassan, M.; Nour, M.; Abdel-Monem, Y.; Abdelkhalik, A. Evaluation of fire performance of linear low-density polyethylene containing novel intumescent flame retardant. J. Therm. Anal. Calorim. 2017, 130, 1031-1041. [CrossRef]

32. Ullah, S.; Ahmad, F. Effects of zirconium silicate reinforcement on expandable graphite based intumescent fire retardant coating. Polym. Degrad. Stab. 2014, 103, 49-62. [CrossRef]

33. Deng, C.L.; Du, S.; Zhao, J.; Shen, Z.; Deng, C.; Wang, Y. An intumescent flame retardant polypropylene system with simultaneously improved flame retardancy and water resistance. Polym. Degrad. Stab. 2014, 108, 97-107. [CrossRef]

34. Zheng, Z.; Liu, Y.; Zhang, L.; Wang, H. Synergistic effect of expandable graphite and intumescent flame retardants on the flame retardancy and thermal stability of polypropylene. J. Mater. Sci. 2016, 51, 5857-5871. [CrossRef]

35. Hu, Q.; Peng, P.; Peng, S.; Liu, J.; Liu, X.; Zou, L.; Chen, J. Flame-retardant epoxy resin based on aluminum monomethylphosphinate. J. Therm. Anal. Calorim. 2017, 128, 201-210. [CrossRef]

36. Nikolic, M.; Nguyen, H.; Daugaard, A.; Löf, D.; Mortensen, K.; Barsberg, S.; Sanadi, A. Influence of surface modified nano silica on alkyd binder before and after accelerated weathering. Polym. Degrad. Stab. 2016, 126, 134-143. [CrossRef]

37. Shi, Y.; Wang, G. Influence of PEPA-containing polyether structure on fire protection of transparent fire-resistant coatings. J. Coat. Technol. Res. 2016, 13, 457-468. [CrossRef]

38. Hu, X.; Wang, G.; Huang, Y. Study on the preparation and properties of novel transparent fire-resistive coatings. J. Coat. Technol. Res. 2013, 10, 717-726. [CrossRef]

39. Wang, G.; Huang, Y.; Hu, X. Synthesis of a novel phosphorus-containing polymer and its application in amino intumescent fire resistant coating. Prog. Org. Coat. 2013, 76, 188-193. [CrossRef] 